\title{
Editorial
}

\section{Is this the new sociology of science? An editorial}

We all know that Charles Darwin arrived at the great synthesis of evolution working alone in the seclusion of Down House (yet even he encountered some publication problems!) and that Albert Einstein also worked in isolation in the Patent Office in Bern. Scientists working alone can continue to make great discoveries, but in the past half century the nature of much of scientific research has undergone major changes. These changes are partly due to the tremendous expansion of the research community and institutions, which in former times consisted of a handful of individuals, but have increased in size by one or more orders of magnitude. A further consequence has been the astronomical growth in the scientific literature, which has - by necessity - led to increasing specialization. Yet another source of change has been the evolution in nearly all the sciences from a situation where science could be carried on with simple, rather inexpensive equipment, to where complex and costly equipment is required. Very large amounts of money are required for cyclotrons or super-telescopes or for gene-sequencing and expression, for example, and for the specialized personnel needed for their operation.

Research carried out by an individual has thus frequently been replaced by research carried out by a team, and sometimes the team is extremely large. For example, a recent publication in Science on the gene sequence of rice had over 100 authors. It is within a team that most research students or post-docs now obtain their training and this provides a dilemma. Research, like other human endeavours, requires dedication and objectives; the objective in research is to discover new phenomena, to be first, since being second is redundant, and to be the best, since priority alone may not suffice if the quality of the work is not excellent. What is the position of those who are members of a large team that is concerned with searching for a new sub-atomic particle or sequencing the genome of a species?

If the research is organized in such a way that all the participants are involved in the steady progress of the investigation this may not cause problems. If the various operations in the investigation are in separate segregated groups, it may 
be difficult for individuals to feel the sense of achievement that ought to come out of a new discovery. Indeed, if the discovery involves an important new insight, which surely occurs to only one or two members of the group, the others must be 'also-rans'. What do these individuals feel that they can report about their participation in the work and what they have accomplished in their period of research study? I suppose they can regard this as good training to prepare them for independent work, but where will they get this? In many instances this leads to a series of postdoctoral research positions in which they gradually move up the seniority pole. In other cases the individual moves into a new employment not involving research, but in which his previous exposure to research has provided the mental training that facilitates the solution of problems.

A further difficulty arises in the publication of research results. How do we identify which individual in the list of authors, has done what, and, in particular, who has provided the original insights? Some journals now indicate by asterisk the two individuals 'who have contributed equally' to the work. This seems a curious device, since it implies that the rest are just hangers-on. There must be particular difficulties in cases such as the sequence of the genome referred to above. How do we know what $\mathrm{X}$ did?

There is a related problem that has recently been highlighted by Peter Lawrence in Nature (21 February 2002) as what he calls 'Rank injustice'. This refers to the practice in which the head of a laboratory is cited as an author of a piece of work simply because of his position and regardless of whether he actually participated in any way. There are some famous accounts of this. In Canada, the discovery of insulin was such a case and the injustice reverberated down the years. The discovery was made in the Department of Physiology at the University of Toronto. A surgeon, Fred Banting came to the Professor, J. J. R. Macleod with the idea of trying to find the active substance in the pancreas by tying the duct and allowing the acinar tissue to degenerate. He was given space and a summer student, Charles Best, to carry out the measurement of blood sugar. During that summer, while Macleod was taking his annual leave in Scotland, they produced active extracts that were developed into the first processes for preparing insulin. In 1923, the Nobel Prize for Physiology and Medicine was awarded to Banting and Macleod with no mention of Best or others that were concerned in making the endeavour successful. Lawrence quotes the even more reprehensible case of the discovery of streptomycin for which Selman Waksman received the 1952 Prize, although the work was done by a graduate student, Albert Schatz, working alone. In this case, Waksman did not even visit the laboratory once during the four months in which the critical experiments were performed. It became generally believed that the discovery was the work of Waksman alone and Schatz did not receive any credit for it. There are further instances where claims of injustice have been 
invoked, and Nobel Prize awards offer the further difficulty due to the restriction to a maximum of three participants.

These are extreme examples, but the practice of the head of the laboratory gaining most of the credit for a discovery and going on the lecture circuit are by no means uncommon. One of the common excuses these days is that the head of the laboratory wrote the grant application and obtained the money that supported the research. This raises a further question; the grant application must have outlined the theory and scope of the proposed research and the role the student was to carry forward, work that may have been thoroughly defined in the proposal. Surely, in such a case, the 'principal investigator' deserves part of the credit, even for any unpredicted, more exciting results that might have emerged, and indeed it often quite obvious to those in the field who has been the inspiration and driving force behind a paper. As one commentator on Lawrence's article noted, 'quite often principal investigators should be given credit - it is not by chance that some laboratories are productive and others are not'.

It is worth reminding ourselves that this requirement for the contributions of all who participate to be recognized explicitly is not a rule in other human activities. It is the conductor (and maybe the leader) of an orchestra who is noted, not all those who provide the glorious sound; generals are recorded as winning battles, not the private soldiers. You may protest that this is not like research where one is exploring the unknown, but it was 'Columbus' who is remembered as discovering the New World, not all the crew of the Pinta. If research is done in an industrial laboratory, you may contribute to the creation of a product that, hopefully, is of economic benefit to the company where you are employed. In this case, your contributions may or may not be recognized within the confines of the company.

This is all adumbrated under 'team spirit'. Is it only in scientific research that this is not valid? Should one not also accept that enjoying their work may be the compensation that many relish rather than seeing their name in lights? Nevertheless, in academic circles, there is little doubt that invitations to conferences, the award of prizes, and promotion within the establishment are influenced by proper recognition in publication, so such recognition is not unimportant.

Another feature of publication that is a source of controversy and a longstanding irritant is the Impact factor or Citation frequency. This is part of the apparatus of the current world, in which books are rated as 'best-sellers' rather than by their intrinsic merit as literature, a recording of music is 'top of the pops' and a footballer has 'the highest transfer fee'. These are all one of the less agreeable aspects of democracy and mass culture, and all have economic implications.

In the world of scientific publications, there is a self-designated, self-important 
organization, the Institute of Scientific Information, a for-profit organization in the United States, which publishes Current Contents, a journal that lists the contents pages of a large range of scientific publications.

This system of classification can certainly lead to some curious results; for instance, a paper that described a minor improvement to a common analytical method turned out to be one of the most cited papers ever. Reviews, which contain no novel findings, frequently have far more citations than any of the important papers cited within their texts. Let us consider some of the influences of such a citation ranking. Journals will vary enormously in their citation index and this has a self-fulfilling consequence; authors flock to the journals with high citation indices, which thus continue to flourish, whereas other journals with lower indices may wither. It is not uncommon these days for young research workers to talk of their desire to publish in a journal of 'high impact factor'. The citation index can also be applied to institutions. This compounds the issue, and leads students to apply to go to institutions with a high impact factor to become part of a high impact factory, since this improves their chances in career development, because, alas, employing authorities are often influenced by these same factors. One must ask how harmful is this pervasive system?

It will certainly downgrade the impact of workers in unpopular fields or in areas that have yet to attain visibility, e.g. Mendel, before the development of genetics. It may also influence granting bodies, who wish to be sure their money is certain to produce a visible return. There is certainly a great resentment at the self-arrogated importance of the ISI, but it may be that much of this irritation is not primarily at this organization, so much as at the persuasiveness of ranking in our society and its intrusion into the holy sanctuary of science. Do we risk being 'holier than thou'?

Yet another contemporary debate concerns the practice of 'peer review'. Is it prejudiced? Of course it is; however much trouble is taken to make it fair, individual reviewers will have their quirks. Can one make it better? One suggestion is that an article could be published together with the reviewer's comments to form a kind of debating club; for controversial subjects such as 'cold fusion' this could be stimulating. We ought to remember that, outside scientific publishing, the acceptance of a book or an article can be very uncertain. Marcel Proust's 'A la recherche du temps perdu' was submitted to the Nouvelle Revue Francaise, but was rejected on the advice of André Gide. Was it not Trollope who had his first ten novels rejected by publishers? And is it not the rule rather than the exception for new authors of novels to have to hawk their offerings to a succession of publishers?

I much admire the purity of the motives of those who are protesting against any change in the standards that we would like to see applied in science. Is the lesson to be drawn from my diatribe that the sociology of scientific research is in the 
process of change and that some of the old practices and verities will not survive? And as always in periods of change, the new rubs against the old and produces friction.

\section{Arnold Burgen}

I am grateful for the advice and helpful comments on this editorial by members of the Physiology and Medicine section of the Academia Europaea. 